\title{
A Survey on Chinese Elements of English Textbooks in Senior High School
}

\author{
$\operatorname{Bin} \mathrm{Lu}^{1,2,}$, Yirong Wang ${ }^{2}$ \\ ${ }^{1}$ School of Management, Shinawatra University, Bangkok, Thailand \\ ${ }^{2}$ School of Foreign Languages, Luoyang Normal University, Luoyang, China \\ Email address: \\ 2423905702@qq.com (Bin Lu), 527582404@qq.com (Yirong Wang) \\ ${ }^{*}$ Corresponding author
}

To cite this article:

Bin Lu, Yirong Wang. A Survey on Chinese Elements of English Textbooks in Senior High School. International Journal of Literature and Arts. Vol. 8, No. 4, 2020, pp. 259-271. doi: 10.11648/j.ijla.20200804.22

Received: June 22, 2020; Accepted: July 14, 2020; Published: August 4, 2020

\begin{abstract}
In order to help senior middle school students and teachers have a better understanding of Chinese elements in the New Senior English for China (2017) (shortened as NSEFC) textbooks, and help teachers to increase their cultural awareness in English teaching and cultivate students' cultural competence, this study analyzes the content, presentation forms and types of Chinese elements in NSEFC textbooks and takes survey research of questionnaires for students and teachers in two senior high schools. At the same time, the in-depth interview of qualitative research, 15 experts are interviewed to explore the understanding of Chinese elements, cultural awareness and cultural expectations in teaching and learning of users of textbooks. Finally, according to the discussion, some suggestions for English textbook editors and teachers will be proposed, namely Chinese elements are not systematically presented in English textbook, and lack of well designed for different level test on traditional Chinese culture. This will promote the further improvement revision of English textbook. It can also boost students' motivation on Chinese elements culture-related content, which is conducive to enhance their cross cultural awareness and the goal of developing students' cultural competence.
\end{abstract}

Keywords: Chinese Elements, Textbook Evaluation, English Textbooks, Survey Research, Cultural Awareness

\section{Introduction}

Chinese elements refers to images, symbols or customs customarily conceived by the majority of Chinese (including overseas Chinese), condensing the spirit of the Chinese nation's traditional culture, and embodying the dignity of the country and the interests of the nation [1]. The Chinese elements in the textbook represent the traditional cultural spirit of the Chinese nation. English textbooks are an important tool for cultivating language skills in intercultural communication, and an important communication tool for cultural pedagogy [2].

In New Senior English for China (shortened as NSEFC), it stressed that cultural competency reflects the value orientation of the key competences of English subjects, and emphasizes that the cultivation of cultural competency helps students to strengthen national identity and national feelings, strengthen cultural self-confidence, establish a sense of human destiny, learn to do things. Become a civilized and socially responsible person.

With the new curriculum reform strengthening the cultivation of students' cultural awareness, more and more researchers are paying attention to the cultural content in English textbook. The Chinese elements are a symbol and spiritual image, and an important component of world element diversity [3]. In the new curriculum of Chinese perspective, the research on English textbooks is relatively rich, and the research on the cultural content of English textbooks is increasingly perfect [4], but there are few studies on Chinese elements in senior high school English textbooks in the new curriculum perspective and there are few studies concerning Chinese textbooks. So it is urgent to investigate the characteristics of Chinese elements in English textbooks and attitudes of teachers and students, to highlight the 
deficiencies of the exiting problems on Chinese element researches.

\section{Research Problems}

\subsection{Research Problems}

This research defines the research problems are as follows:

1) What's the characteristics of Chinese elements in NSEFC textbooks in terms of content, presentation forms and types?

2) What's the attitudes of teachers and students towards Chinese elements in NSEFC textbooks, their cultural awareness and cultural expectations in teaching and learning?

\subsection{Classification of Chinese Elements}

This survey research on cultural content in English textbook evaluation mainly focus on the basis of three aspects. The first one is to analyze the cultural content of English textbooks from a description perspective, the second one is to classify and analyze the cultural content in textbooks; the third one is to analyze the attitudes towards cultural content in textbooks from a survey perspective. The following are the different categories on Chinese elements in English Textbooks.

Category 1

According to the compilation method of the NSEFC textbooks, the five parts are expanded from the Unit, Contents of Chinese Element, Forms, Section, and Frequency [5]. In the tables 1-5, the "Unit" is the number of units marked in each volumes of textbook, "Contents of Chinese Elements" is the different symbols of Chinese elements in each volumes of textbooks. "Forms" is the presentation forms of Chinese elements in each volumes of textbooks. "Frequency" is the statistical result of the frequency of Chinese elements in the whole unit. In this section, all the Chinese elements are classified by "Pictures", "English description + Pictures", "Pictures + Words", "Words", "English description". "Pictures" refers to the showing of Chinese elements with pictures only. "English description + Pictures" refers to the showing of Chinese elements with English description and pictures. "Pictures + Words" refers to the showing of Chinese elements with pictures and a few words (not a sentence). "English description" refers to the showing of Chinese elements with English description (a sentence of English description or a paragraph of English description). And all the sections in each unit covers Warming up, Pre-reading, Reading, Comprehending, Learning about language, Using language and workbook will be discussed.

Category 2

The second category covers natural elements, cultural elements, and character elements. This classification is based on Ma Yanming's The System Composition of Chinese Elements and Related Problems [6]. The classification results are shown in the Tables 1-5.
According to the participation of human activities, "Chinese elements" can be divided into natural elements, cultural elements, and character elements:

Natural elements The natural elements here are not the general name of the material elements existing in the nature, more accurately speaking, they are the elements of the natural landscape, which are relative to the human and cultural elements and have not been or seldom been influenced by human activities.

Character elements According to whether there is a real person, whether there is fiction, generally can be divided into two categories: one is the history or reality of the objective existence of individuals; the other is fictional and mythological characters.

Cultural elements Compared with natural elements, they are mainly elements influenced by human activities, or creations of human activities. They are generally divided into three categories: material cultural elements, non-material cultural elements and ideological elements.

Based on the analysis of the Chinese elements in the English textbook from the perspective of NSEFC, this paper puts forward some suggestions to improve the students' motivation on Chinese elements culture-related content and enhance their cultural competence in real life, help the English teachers to have an effective and profound culture teaching in teaching practice.

\section{Research Design}

\subsection{Research Objectives}

This survey research focuses on classification and volume of Chinese elements of the widely-used English textbook New Senior English for China published by People's Education Press (NSEFC) — student's book 1-5, and different attitudes to Chinese elements of teachers and students. The research objectives are following:

1) To have an analysis of Chinese elements in NSEFC textbooks in terms of the contents, presentation forms and types;

2) To have a attitudes survey of teachers and students towards Chinese elements in NSEFC textbooks, their cultural awareness and cultural expectations in teaching and learning;

3) To have some suggestions on NSEFC textbooks.

And this research employs tables of Chines elements distribution, Cronbach's Alpha to explain the reliability analysis of teacher and student questionnaires, KMO Test Coefficient to explain the validity analysis of teacher questionnaires and student questionnaires, descriptive statistics including mean to explain teacher's and students' overall evaluation of the cultural content of the textbook, to explain teacher's and students' understanding of Chinese elements and views on the contents, presentation forms and types of Chinese elements in textbooks, and to explain whether teachers pay attention to Chinese cultural teaching in English teaching and consciously improve cultural teaching 
skills and whether students think teachers pay attention to Chinese cultural teaching in education and teaching and consciously improve cultural teaching skills.

\subsection{Research Subjects}

This research focuses on classification and volume of Chinese elements of the widely-used English textbook New Senior English for China published by People's Education Press (NSEFC) - student's book 1-5, and different attitudes towards English teaching experts, school managements, teachers and students.

\subsection{Research Scope}

The research covers the interpretation of Chinese elements contained in English textbook New Senior English for China published by People's Education Press (NSEFC) — student's book 1-5, the topics and proportions are involved in the distribution of Chinese elements in textbooks, and the presentation of Chinese elements in textbooks, etc. In this interpretation of Chinese elements in textbooks, Cui Yiqing pays attention to self-cultivation, self-development, and different people to interpret Chinese elements [7]. In the introduction of Chinese elements into textbooks, Gao Lingbiao, Hu Dingrong pay attention to the relationship between Chinese elements and the subject, making full use of the characteristics of Chinese elements, playing the role of traditional culture in classroom teaching $[8,9]$. In the analysis method, the main analysis refers to content analysis and text analysis, followed by the use of the mix methods on quantitative and qualitative analysis.

This research provides the classification of Chinese elements from the perspective of Multimodality [10]. And according to the content of each unit of Chinese elements in each textbook, the expression forms and types are described and counted.

\subsection{Research Procedures}

This research carries out through two procedures. The first is the internal evaluation analysis. The second is external evaluation survey towards teachers and students from two questionnaires [11]. In first part, that is internal evaluation, the text analysis method is used to show contents, presentation forms and types of Chinese elements in NSEFC textbooks, so that the Chinese elements in the textbooks are analyzed. In the second part, that is external evaluation, questionnaires survey and in-depth interview method are used to discuss different attitudes on Chinese elements in NSEFC textbooks about teachers and students, cultural awareness and cultural expectations of students and teachers in teaching and learning [12].

\subsection{Research Sampling}

In order to ensure the authenticity and validity of the data, all data are first-hand information. And subjects come from School A and B (each school collects 33 English teachers and 300 students as sampling). The selected students in the survey is studying in different grades (100 students in each grade).
The selected teacher are all English teachers and they all have different teaching ages and education backgrounds. Among the teachers who answer questionnaire, there are 5 teachers are invited to be interviewed from School A and 5 teachers are invited to be interviewed from School B.

The questionnaires for students from School A were handed out on November 4th, 2019. And the questionnaires for students from School B were handed out on November 7th, 2019. Before giving the questionnaires, the researcher gave a brief introduction to the students and teachers. Then the students were asked to answer 15 questions according to the each of the questionnaire in 25 minutes, and they were told that they can answer according to their own opinion. The questionnaires for teachers from School A and School B were handed out on the next day after the students' questionnaires were done. And teachers interview were also done on that day. With the exception of the 10 teachers, the author interviewed 2 headmasters came from School A and School B, and three experts in the field of basic education, some of them were interviewed by telephone.

Among them, there are 30 valid questionnaires for teachers and 270 valid questionnaires for students (from School A) and there are 30 valid questionnaires for teachers and 293 valid questionnaires for students (from School B). All data are analyzed by SPSS 17.0 and presented by Means and Percentage.

\subsection{Research Methods}

Quantitative Research In quantitative research obtained from survey questionnaires will be coded and input into software computer for calculation using descriptive statistics (mean, standard deviation, and etc) to analyze and explain personal profiles of the respondents.

1) Text Analysis Method Text analysis method refers to reading and analyzing textbooks, grasping the knowledge content of textbooks, and conducting a comprehensive and detailed analysis of the content of each part of textbooks. Based on NSEFC, this paper finds out the content, presentation forms, and types of Chinese elements in NSEFC.

2) Questionnaire Survey Questionnaire survey refers to the form used for statistics and investigation to express questions in the way of questionnaire questions. The questionnaire method is a method that researchers use this kind of controlled measurement to measure the research problems, so as to collect reliable data. Most of the questionnaires are sent by mail, individual distribution or collective distribution.

In the practice of research, the users of textbooks as important participants must participate in the research process. So in order to make this survey more accurate, two questionnaires were designed for teachers and students. 33 English teachers and 300 students from School A. And another 33 English teachers and 300 students from School B. The questionnaire mainly conducts on teachers and students attitudes towards Chinese elements in NSEFC textbooks. The two questionnaires also cover the cultural awareness and 
cultural expectation of teachers and students.

Qualitative Research In qualitative research obtained from in-depth interview will be analyzed using content analysis. In order to highlight the shortcomings of the questionnaire survey and make the research data more authentic and reliable, the researcher interviews ten teachers, three experts and two headmasters in basic education sampling. This interview is used to understand the current situation of Chinese element culture teaching in NSEFC textbooks, so as to further improve the efficiency use of English textbooks in senior high schools.

This research uses in-depth interview to collect qualitative data from key informants (different attitude of teachers and students) and uses survey questionnaire to collect data from the respondents.

\subsection{Research Hypothesis}

Three hypothesis have been set and tested in later data analysis.

H1: There are fewer Chinese elements contents in NSEFC textbooks.

$\mathrm{H} 2$ : There are single presentation forms of Chinese elements in NSEFC textbooks.

H3: Teachers and students who have good understanding of Chinese elements, think that learning Chinese elements contents is an important part in cross culture teaching and learning process.

\subsection{Data Collection}

The method to collect data are following:

1) To find and select classification types on Chinese element based on Xiaotang Cheng's method of evaluating English textbooks, then sort and summarize the Chinese elements;

2) To investigate attitudes of teachers and students toward the Chinese elements in English textbooks design;

3) To design survey questionnaire on social attitude toward Chinese elements;

4) To design the in-depth interview questions;

5) To collect the data, and make data analysis;

\section{Data Analysis and Discussion}

The objectives of this study are to 1) to analyze Chinese elements in NSEFC textbooks in terms of the contents, presentation forms and types, and 2) to survey towards teachers and students on Chinese elements in NSEFC textbooks, their cultural awareness and cultural expectations in teaching and learning. In order to test the research hypotheses, the research employed tables of China elements distribution, Cronbach's Alpha to explain the reliability analysis of teacher questionnaires and student questionnaires, KMO Test Coefficient to explain the validity analysis of teacher questionnaires and student questionnaires, descriptive statistics including mean to explain teacher's and students' overall evaluation of the cultural content of the textbook, to explain teacher's and students' understanding of Chinese elements and views on the contents, presentation forms and types of Chinese elements in textbooks, and to explain whether teachers pay attention to Chinese cultural teaching in English teaching and consciously improve Chinese cultural teaching skills and whether students think teachers pay attention to Chinese cultural teaching in education and teaching and consciously improve cultural teaching skills.

Part 1 Internal Evaluation

Category 1:

The classification result is shown in the tables Table 1 to Table 5.

Table 1. Contents and Presentation Forms in Student's Book 1.

\begin{tabular}{|c|c|c|c|c|}
\hline Unit & Contents of Chinese Elements & Forms & Section & Frequency \\
\hline \multirow{4}{*}{ Unit 1} & $\begin{array}{l}\text { Beijing/Shanghai/Guangzhou/Chongqin } \\
\text { g/Changchun }\end{array}$ & words & $\begin{array}{l}\text { Learning about Language-discovering useful } \\
\text { structures }\end{array}$ & 4 \\
\hline & China/ Peking Opera/Great Wall & words & Workbook-listening & \\
\hline & Chinese people & words & Workbook-talking & \\
\hline & China/CCTV team & words & Workbook-using words and expression & \\
\hline \multirow{7}{*}{ Unit 2} & China/Chinese/Chinese English & English description & Reading & 8 \\
\hline & Chinese person & words & Learning about language & \multirow{13}{*}{13} \\
\hline & Chinese friends & words & Workbook-talking & \\
\hline & Deng Xiaoping & English description & Workbook-using words and expression & \\
\hline & The late Qing Dynasty & words & Workbook-reading task & \\
\hline & CCTV 9 & words & Workbook-listening task & \\
\hline & CCTV 9 & words & Workbook-writing task & \\
\hline \multirow{7}{*}{ Unit 3} & The Mekong River & picture + words & Pre-reading & \\
\hline & Journey down the Mekong & English description + pictures & reading & \\
\hline & Mekong/China/Dali & words & Comprehending & \\
\hline & The Mekong River/Qinghai Province & words & $\begin{array}{l}\text { Learning about Language-discovering useful } \\
\text { structures }\end{array}$ & \\
\hline & Journey down the Mekong & English description + pictures & Using language-reading and discussing & \\
\hline & The Mekong River & English description & Using language-listening and speaking & \\
\hline & To Wang Lun & English description & Reading for fun & \\
\hline
\end{tabular}




\begin{tabular}{|c|c|c|c|c|}
\hline Unit & Contents of Chinese Elements & Forms & Section & Frequency \\
\hline \multirow{9}{*}{ Unit 4} & Tibet/The Mekong River & words & Workbook-listening & \multirow{9}{*}{5} \\
\hline & The Mekong River/ the South China Sea & words & Workbook-using words and expression & \\
\hline & Map of China & pictuers & Workbook-using structures & \\
\hline & China & words & Workbook-listening task & \\
\hline & The Mekong River & words & Workbook-reading task & \\
\hline & Tang shan & picture + words & Warming up & \\
\hline & TangShan Earthquake & English description + pictures & Reading & \\
\hline & Lijiang, Yunnan/Lhasa, Tibet/China & words & Using language-reading and writing & \\
\hline & China & words & Workbook-listening & \\
\hline \multirow{5}{*}{ Unit 5} & Sun Yat-sent & English description + pictures & Pre-reading & \multirow[t]{5}{*}{6} \\
\hline & China & words & $\begin{array}{l}\text { Learning about Language-discovering useful } \\
\text { structures }\end{array}$ & \\
\hline & Confucius/Qian Xuesen & pictures + words & Workbook-talking & \\
\hline & China/Mao Zedong/Nanjing & words & Workbook-using structure & \\
\hline & Wang Xuan/Li Shizhen & pictures + words & Workbook-speaking-task & \\
\hline
\end{tabular}

Table 2. Contents and Presentation Forms in Student's Book 2.

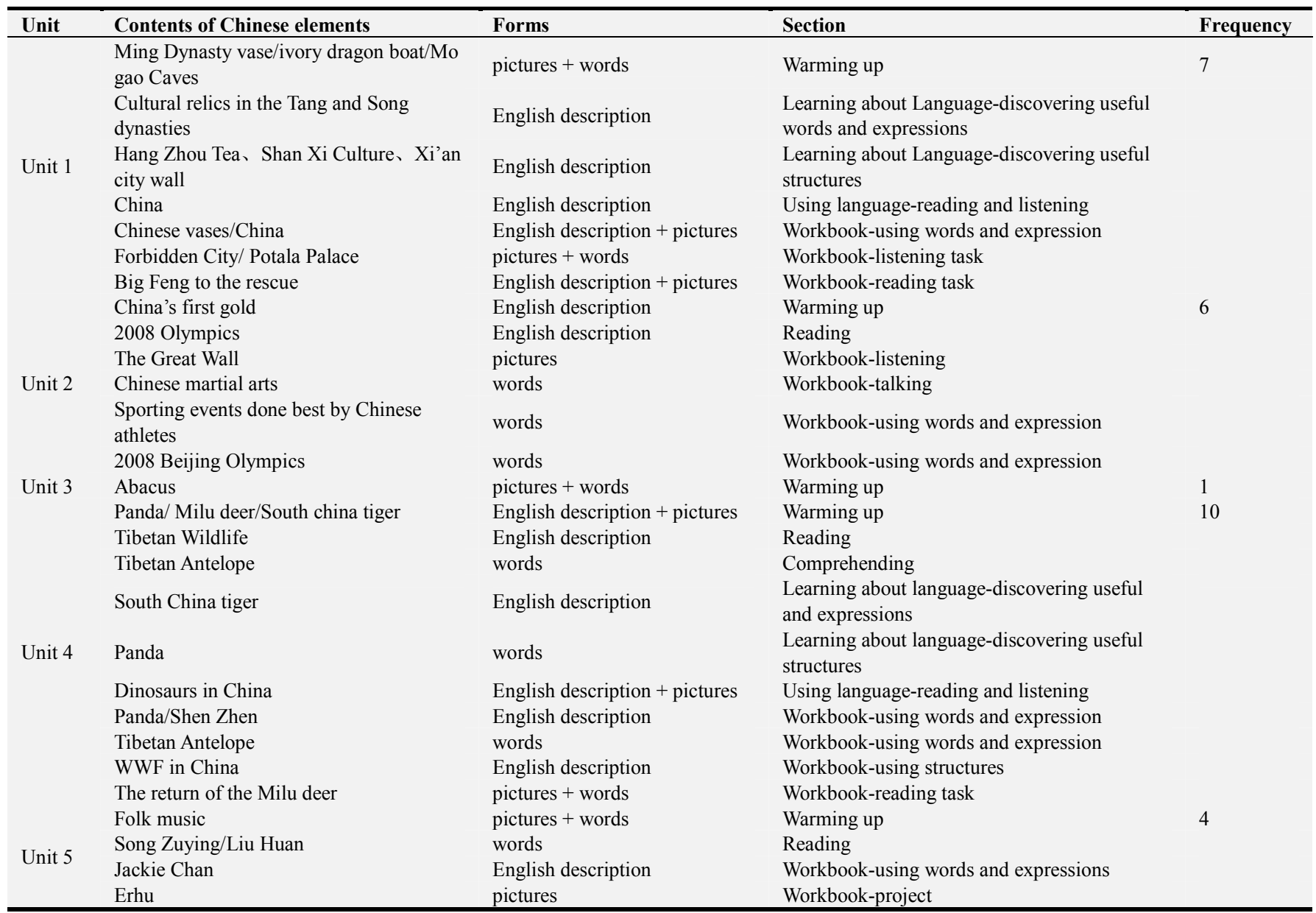

Table 3. Contents and Presentation Forms in Student's Book 3.

\begin{tabular}{llll}
\hline Unit & Contents of Chinese elements & Forms & Section \\
\hline & Mid-autumn & English description & Warming up \\
& The Dragon Boat & English description + pictures & Reading \\
& Festival/Mid-Autumn/Spring Festival & & Learning about Language-discovering useful \\
Unit 1 & Bei Hai Park/Spring festival & words & structures \\
& Cowboy and Weaver & English description + pictures & Using language-reading and writing \\
& Qiqiao Festival & words & Using language-reading and writing \\
& Chinese Spring Festival & pictures + words & Workbook-talking \\
\hline
\end{tabular}




\begin{tabular}{llll}
\hline Unit & Contents of Chinese elements & Forms & Section \\
\hline \multirow{2}{*}{ An igloo in Harbin } & Harbin & English description + pictures & Workbook-reading task \\
& Minorities holidays in china & words & Workbook-reading task \\
Unit 2 & Dumplings & pictures + words & Workbook-project \\
Unit 3 & Tibet & words & Using language-reading and discussing \\
& Yang Liwei & words & Learning about language-discovering useful words \\
Unit 4 & Potala Palace & English description + pictures & Workbook-listening \\
& Comparison between China and Canada & English description & Workbook-using words and expression \\
& Map of China & pictures & Workbook-listening \\
Unit 5 & Tibet/Mongolia & words & Workbook-talking \\
& Yi Chang & English description & Workbook-using words and expression \\
\end{tabular}

Table 4. Contents and Presentation Forms in Student's Book 4.

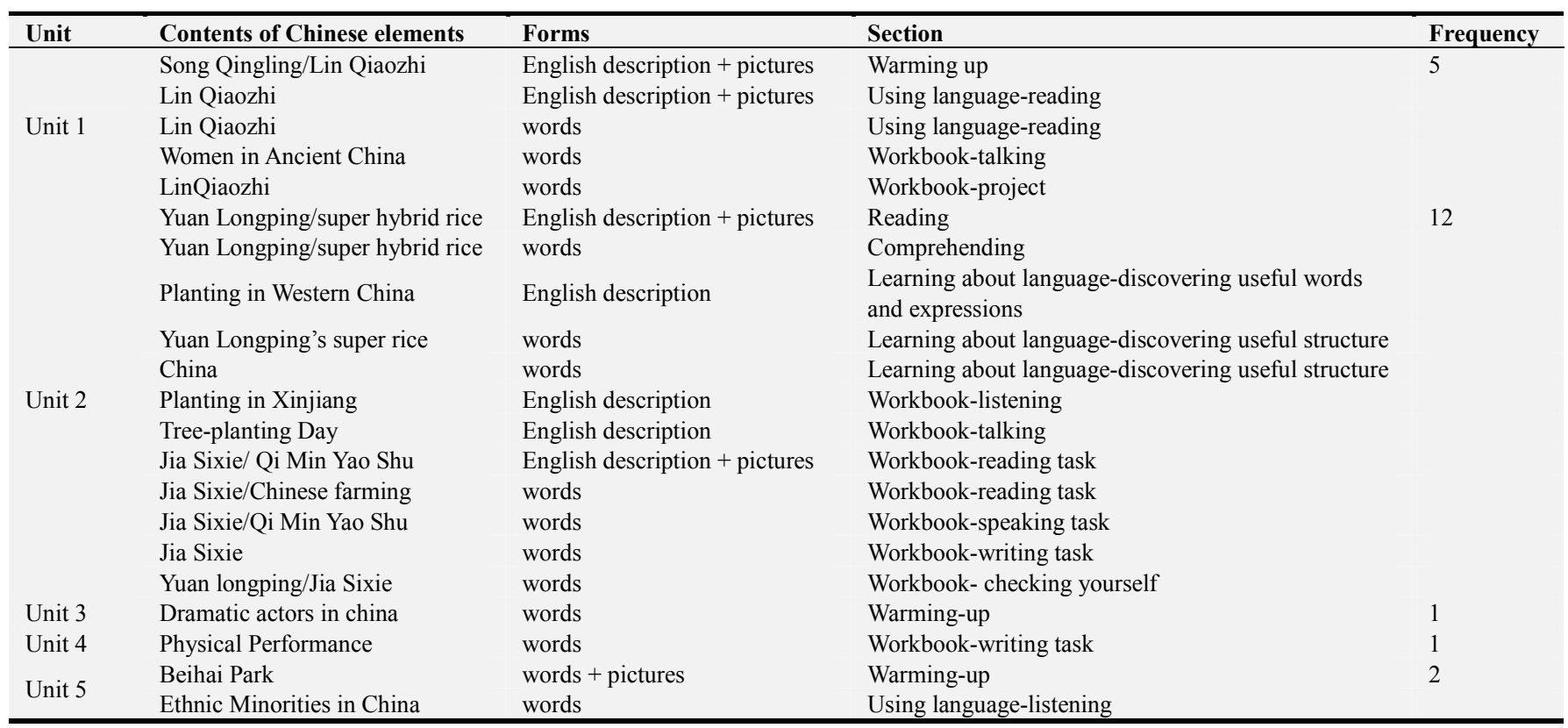

Table 5. Contents and Presentation Forms in Student's Book 5.

\begin{tabular}{|c|c|c|c|c|}
\hline Unit & Contents of Chinese elements & Forms & Section & Frequency \\
\hline \multirow{4}{*}{ Unit 1} & Qian Xuesen & words & Using language-listening and speaking & 4 \\
\hline & China Aerospace & pictures & Using language-listening and speaking & \\
\hline & Chinese achievements in space & words & Using language-listening and speaking & \\
\hline & Zhang Heng & words + pictures & Workbook-writing task & \\
\hline \multirow{3}{*}{ Unit 4} & Wang Fujing & words & workbook-using structures & 3 \\
\hline & Jia Sixie & words & Workbook-reading task & \\
\hline & The development of computer in China & English description & Workbook-reading task & \\
\hline Unit 5 & China emergency call & words & Workbook-speaking task & 3 \\
\hline
\end{tabular}

From the perspective of Chinese element distribution section, Chinese elements in each book of NSEFC are not evenly distributed. There are 5 units in each Student's Book in NCEFC textbooks and there are 25 units in the five student's books, of which 23 are related to Chinese elements, accounting for $92 \%$ of the total number of units. Among them, Student's Book 1, 2, 3, 4 are all involves five units in each book, while the Student's Book 5 are only three units involved, so it can be seen that Chinese elements basically involves each unit. But Chinese elements in each book of NSEFC are not evenly distributed. According to the statistical results of the data, the average of Chinese elements are involved in each unit is five times, but the actual distribution of each unit in each textbook is uneven. And this distribution can be seen that this version of textbook is basically presented with one unit as the lead, and the characteristics of the other units presented sporadically. Most of the Chinese elements are distributed in the section of "Workbook".

The learning presented in multiple ways is conducive to cultivating students' active understanding of English textbooks [13], inspiring students to constructively think about articles, and enabling students to effectively grasp the cultural information of discourse [14]. In this formation, it is hard for students to communicate Chinese culture in English and to present English in the brain cognitive system [15]. Besides, the expression of Chinese culture is unfavorable. 
From the distribution of Chinese elements in each volume, the distribution of Chinese elements in the textbooks is not balanced. They distribute too many items on student book 1 to 3 and student book 4 and 5 are less. The Chinese cultural content in the English textbook should be evenly distributed in each textbook, and help senior high school students to receive cross cultural education and learning at all stages. With the grade growth of senior high school students, especially for the transition from senior high school to college, the amount of Chinese cultural content and the depth of topics should be expanded.

Category 2:

The classification results are shown in the Figure 1.

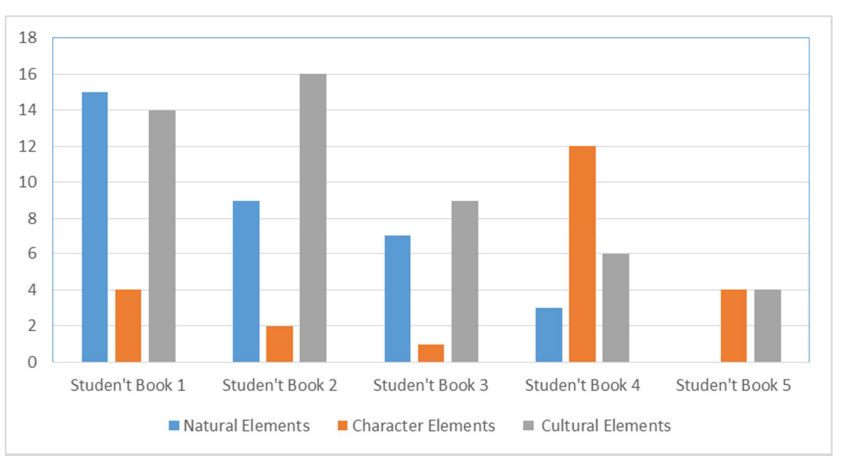

Figure 1. Chinese Elements Classification Form.

As shown in the figure 1, in the student's book 1-5, the proportion of cultural elements and natural elements is relatively large, and the topic range is broad, which is consistent with the age, physical and mental development of high school students, which able to attract students' interest. However, the proportion of character elements is the smallest. Character elements, cultural elements and natural elements are not evenly distributed in the five textbooks. In the first three textbooks, the number of natural and cultural elements is higher than that of characters elements. In the student's book 4, the number of character elements is the largest, followed by cultural elements, and then natural elements. However, in the student's book 5, character elements and cultural elements appear in a small amount, and there are no natural elements. The frequency of Chinese elements in NSEFC textbooks changes too much, although they all reach a high frequency, but it is not conducive to the stability of students' emotional attitude and cultural awareness, so the frequency needs to be adjusted.

Under the background of multi-cultural knowledge, the real cultural learning cannot lie in the understanding of simple cultural knowledge, but emphasizes the learners who have cultural literacy and the multi-cultural vision. The content of Chinese elements in character elements is able to help students to learn predecessors' spirit, thoughts and culture, and construct cultural concepts in the interactive learning process, so as to enhance cultural awareness, cultural literacy, and achieve the sublimation of self-feelings finally.

Part 2 External Evaluation-The Reliability and Validity Analysis of Questionnaire.

Table 6. Reliability Analysis of Teacher Questionnaires Reliability Analysis.

\begin{tabular}{ll}
\hline Cronbach's Alpha & N of Items \\
\hline 847 & 15 \\
\hline
\end{tabular}

According to the Table 6 above, it can be seen that the Cronbach's Alpha $=0.847(>0.8)$, which indicates that the questionnaire of teachers is reliable.

Table 7. Validity Analysis of Teacher Questionnaires KMO and Bartlett test.

\begin{tabular}{lll}
\hline Kaiser-Meyer-olkin Measure of Sampling & $\mathbf{. 6 1 2}$ \\
\hline \multirow{3}{*}{ Bartlett' Test of Sphericity } & Approx. Chi-Square & 354.744 \\
& df & 105 \\
& Sig. & .000 \\
\hline
\end{tabular}

From the data of the Table 7, KMO Test Coefficient of this questionnaire is $0.612(>0.5)$, which means that validity of this questionnaire is high, that is to say, this questionnaire is valid. Besides, Sig is $0.000(<0.001)$ that reaches a significant level.

Table 8. Reliability Analysis of Student Questionnaires Reliability Analysis.

\begin{tabular}{ll}
\hline Cronbach's Alpha & N of Items \\
\hline .833 & 15 \\
\hline
\end{tabular}

According to the Table 8 above, it can be seen that the Cronbach's Alpha $=0.833(>0.8)$, which indicates that the questionnaire of students is reliable.

Table 9. Validity Analysis of Student Questionnaires KMO and Bartlett test.

\begin{tabular}{lll}
\hline Kaiser-Meyer-olkin Measure of Sampling & & \\
& & $\mathbf{6 1 2}$ \\
Bartlett' Test of Sphericity & Approx. Chi-Square & 354.744 \\
& df & 105 \\
& Sig. & .000 \\
\hline
\end{tabular}

From the data of the Table 9, KMO Test Coefficient of this questionnaire is $0.612(>0.5)$, which means that validity of this 
questionnaire is high, that is to say, this questionnaire is valid. Besides, Sig is $0.000(<0.001)$ that reaches a significant level.

Part 3 External Evaluation-Data Analysis of Teacher

\section{Questionnaires}

Questions 1-4 are mainly about the teacher's overall evaluation of the cultural content of the textbook.

Table 10. School A-Teacher Questionnaires of Q1-Q4.

\begin{tabular}{|c|c|c|c|c|c|c|c|}
\hline Questions & SD & Mean & Strongly Disagree & Disagree & Not Sure & Agree & Strongly Agree \\
\hline 1 & 1.008 & 3.53 & $3.3 \%$ & $10 \%$ & $33.3 \%$ & $36.7 \%$ & $16.7 \%$ \\
\hline 2 & 1.073 & 3.77 & $3.3 \%$ & $10.0 \%$ & $20.0 \%$ & $40.0 \%$ & $26.7 \%$ \\
\hline 3 & .980 & 4.07 & $3.3 \%$ & $3.3 \%$ & $14.3 \%$ & $43.3 \%$ & $36.7 \%$ \\
\hline 4 & 1.196 & 3.50 & $6.7 \%$ & $10.0 \%$ & $36.7 \%$ & $20.0 \%$ & $26.7 \%$ \\
\hline
\end{tabular}

Table 11. School B-Teacher Questionnaires of Q1-Q4.

\begin{tabular}{|c|c|c|c|c|c|c|c|}
\hline Questions & SD & Mean & Strongly Disagree & Disapprove & Not Sure & Agree & Strongly Agree \\
\hline 1 & 1.016 & 3.47 & $0.0 \%$ & $21.9 \%$ & $25 \%$ & $37.5 \%$ & $15.6 \%$ \\
\hline 2 & 1.181 & 2.66 & $12.5 \%$ & $46.9 \%$ & $9.4 \%$ & $25.0 \%$ & $6.3 \%$ \\
\hline 3 & 1.014 & 3.06 & $0.0 \%$ & $37.5 \%$ & $28.1 \%$ & $25.0 \%$ & $9.4 \%$ \\
\hline 4 & 0.924 & 3.28 & $3.1 \%$ & $15.6 \%$ & $37.5 \%$ & $37.5 \%$ & $6.3 \%$ \\
\hline
\end{tabular}

The average point of Mean in the Question 1-4 in School A is $3.71(>3.5)$ and the average point of Mean in the Question $1-4$ in School B is $3.12(>2.5)$, which shows that teachers in School A are relatively more optimistic about the Chinese cultural content of the textbook than teachers in School B.

Questions 5-12 are mainly about teachers' understanding of Chinese elements and their views on the contents, presentation forms and types of Chinese elements in textbooks.

Table 12. School A-Teacher Questionnaires of Q5-Q12.

\begin{tabular}{|c|c|c|c|c|c|c|c|}
\hline Item & SD & Mean & Strongly Disagree & Disagree & Not Sure & Agree & Strongly Agree \\
\hline 5 & .681 & 4.53 & $0.0 \%$ & $0.0 \%$ & $10.0 \%$ & $26.7 \%$ & $63.3 \%$ \\
\hline 6 & .702 & 4.30 & $0.0 \%$ & $0.0 \%$ & $13.3 \%$ & $43.3 \%$ & $43.3 \%$ \\
\hline 7 & .960 & 4.10 & $0.0 \%$ & $6.7 \%$ & $20.0 \%$ & $30.0 \%$ & $43.3 \%$ \\
\hline 8 & 0.860 & 4.13 & $0.0 \%$ & $3.3 \%$ & $20.0 \%$ & $36.7 \%$ & $40.0 \%$ \\
\hline 9 & 0.681 & 4.47 & $0.0 \%$ & $0.0 \%$ & $10.0 \%$ & $33.3 \%$ & $56.7 \%$ \\
\hline 10 & .890 & 4.03 & $0.0 \%$ & $3.3 \%$ & $26.7 \%$ & $33.3 \%$ & $36.7 \%$ \\
\hline 11 & 1.042 & 3.87 & $0.0 \%$ & $10.0 \%$ & $30.0 \%$ & $23.3 \%$ & $36.7 \%$ \\
\hline
\end{tabular}

Table 13. School B-Teacher Questionnaires of Q5-Q12.

\begin{tabular}{|c|c|c|c|c|c|c|c|}
\hline Questions & SD & Mean & Strongly Disagree & Disagree & Not Sure & Agree & Strongly Agree \\
\hline 5 & 0.965 & 4.19 & $0.0 \%$ & $6.3 \%$ & $18.8 \%$ & $25.0 \%$ & $50.0 \%$ \\
\hline 6 & 0.924 & 4.28 & $0.0 \%$ & $6.3 \%$ & $12.5 \%$ & $28.1 \%$ & $53.1 \%$ \\
\hline 7 & 0.822 & 2.97 & $0.0 \%$ & $31.3 \%$ & $43.8 \%$ & $21.9 \%$ & $3.1 \%$ \\
\hline 8 & 1.073 & 2.59 & $12.5 \%$ & $40.6 \%$ & $28.1 \%$ & $12.5 \%$ & $6.3 \%$ \\
\hline 9 & 1.039 & 4.22 & $3.1 \%$ & $3.1 \%$ & $15.6 \%$ & $25.0 \%$ & $53.1 \%$ \\
\hline 10 & 0.827 & 3.34 & $0.0 \%$ & $12.5 \%$ & $50.0 \%$ & $28.1 \%$ & $9.4 \%$ \\
\hline 11 & 0.897 & 3.97 & $0.0 \%$ & $6.3 \%$ & $21.9 \%$ & $40.6 \%$ & $31.3 \%$ \\
\hline 12 & 0.942 & 3.13 & $0.0 \%$ & $28.1 \%$ & $40.6 \%$ & $21.9 \%$ & $9.4 \%$ \\
\hline
\end{tabular}

The average point of Mean in the Question 5-12 in School A is $4.1(>3.5)$ and the average point of Mean in the Question $5-12$ in School B is $3.58(>2.5)$, which shows that teachers in School A are relatively more optimistic about the Chinese elements content, presentation forms and types of the textbook than teachers in School B.

Questions 13-15 are mainly about whether teachers pay attention to cultural teaching in English teaching and consciously improve cultural teaching skills.

Table 14. School A-Teacher Questionnaires of Q13-Q15.

\begin{tabular}{lllllll}
\hline Questions & SD & Mean & Strongly Disagree & Disagree & Not Sure & Agree \\
\hline 13 & .702 & 4.30 & 0 & 0 & $13.3 \%$ & $43.3 \%$ \\
14 & .724 & 4.40 & 0 & 0 & $13.3 \%$ & $33.3 \%$ \\
15 & .547 & 4.67 & 0 & 0 & $3.3 \%$ & $26.7 \%$ \\
\hline
\end{tabular}

Table 15. School B-Teacher Questionnaires of Q13-Q15.

\begin{tabular}{|c|c|c|c|c|c|c|c|}
\hline Questions & SD & Mean & Strongly Disagree & Disagree & Not Sure & Agree & Strongly Agree \\
\hline 13 & 0.840 & 3.56 & $0 \%$ & $9.4 \%$ & $37.5 \%$ & $40.6 \%$ & $12.5 \%$ \\
\hline 14 & 0.672 & 3.25 & $0 \%$ & $9.4 \%$ & $59.4 \%$ & $28.1 \%$ & $3.1 \%$ \\
\hline 15 & 0.859 & 3.31 & $0 \%$ & $15.6 \%$ & $46.9 \%$ & $28.1 \%$ & $9.4 \%$ \\
\hline
\end{tabular}


The average point of Mean in the Question 13-15 in School $\mathrm{A}$ is $4.45(>3.5)$ and the average point of Mean in the Question $13-15$ in School B is 3.37 (>2.5), which shows that teachers in School A are relatively more optimistic about the cultural teaching than teachers in School B.
Part 4 External Evaluation-Data Analysis of Student Questionnaires.

Questions 1-3 are mainly for students' overall evaluation of the cultural content in NSEFC.

Table 16. School A-Student Questionnaires of Q1-Q4.

\begin{tabular}{|c|c|c|c|c|c|c|c|}
\hline Questions & SD & Mean & Strongly Disagree & Disagree & Not Sure & Agree & Strongly Agree \\
\hline 1 & 1.069 & 3.49 & $4.1 \%$ & $13.0 \%$ & $32.6 \%$ & $31.1 \%$ & $19.3 \%$ \\
\hline 2 & 1.086 & 3.29 & $4.8 \%$ & $19.6 \%$ & $31.9 \%$ & $29.3 \%$ & $14.4 \%$ \\
\hline 3 & .964 & 3.80 & $2.6 \%$ & $4.8 \%$ & $28.5 \%$ & $38.5 \%$ & $25.6 \%$ \\
\hline 4 & 1.011 & 3.25 & $3.3 \%$ & $18.9 \%$ & $39.6 \%$ & $25.6 \%$ & $12.6 \%$ \\
\hline
\end{tabular}

Table 17. School B-Student Questionnaires of Q1-Q4.

\begin{tabular}{|c|c|c|c|c|c|c|c|}
\hline Questions & SD & Mean & Strongly Disagree & Disagree & Not Sure & Agree & Strongly Agree \\
\hline 1 & 0.954 & 3.61 & $2.4 \%$ & $9.6 \%$ & $29.4 \%$ & $42.0 \%$ & $16.7 \%$ \\
\hline 2 & 1.115 & 3.16 & $6.5 \%$ & $22.5 \%$ & $33.1 \%$ & $24.6 \%$ & $13.3 \%$ \\
\hline 3 & 0.992 & 3.49 & $1.7 \%$ & $13.0 \%$ & $38.6 \%$ & $28.3 \%$ & $18.4 \%$ \\
\hline 4 & 0.947 & 3.78 & $1.4 \%$ & $6.5 \%$ & $30.4 \%$ & $36.2 \%$ & $25.6 \%$ \\
\hline
\end{tabular}

The average point of Mean in the Question 1-4 in School A is $3.45(>2.5)$ and the average point of Mean in the Question $1-4$ in School B is 3.51 (>3.5), which shows that students in School B are relatively more optimistic about the cultural contents than students in School A.

Questions 5-12 are mainly about students' understanding of Chinese elements and their views on the contents, presentation forms and types of Chinese elements in textbooks.

Table 18. School A-Student Questionnaires of Q5-Q12.

\begin{tabular}{|c|c|c|c|c|c|c|c|}
\hline Questions & SD & Mean & Strongly Disagree & Disagree & Not Sure & Agree & Strongly Agree \\
\hline 5 & 1.1 & 3.4 & $5.9 \%$ & $14.8 \%$ & $29.6 \%$ & $29.6 \%$ & $20.0 \%$ \\
\hline 6 & 1.0 & 4.1 & $2.6 \%$ & $4.8 \%$ & $17.0 \%$ & $34.1 \%$ & $41.5 \%$ \\
\hline 7 & 1.1 & 3.2 & $6.7 \%$ & $20.4 \%$ & $33.3 \%$ & $23.7 \%$ & $15.9 \%$ \\
\hline 8 & 1.0 & 3.5 & $3.3 \%$ & $10.4 \%$ & $35.6 \%$ & $34.1 \%$ & $16.7 \%$ \\
\hline 9 & 1.1 & 3.3 & $5.2 \%$ & $15.2 \%$ & $35.9 \%$ & $28.9 \%$ & $14.8 \%$ \\
\hline 10 & 1.0 & 3.5 & $3.3 \%$ & $12.6 \%$ & $36.3 \%$ & $28.9 \%$ & $18.9 \%$ \\
\hline 11 & 1.2 & 3.4 & $8.5 \%$ & $12.6 \%$ & $29.6 \%$ & $31.5 \%$ & $17.8 \%$ \\
\hline
\end{tabular}

Table 19. School B-Student Questionnaires of Q5-Q12.

\begin{tabular}{|c|c|c|c|c|c|c|c|}
\hline Questions & SD & Mean & Strongly Disagree & Disagree & Not Sure & Agree & Strongly Agree \\
\hline 5 & 0.7 & 4.5 & $0.3 \%$ & $0.3 \%$ & $11.6 \%$ & $19.5 \%$ & $68.3 \%$ \\
\hline 6 & 0.7 & 4.7 & $0.0 \%$ & $1.0 \%$ & $17.5 \%$ & $13.3 \%$ & $78.2 \%$ \\
\hline 7 & 1.1 & 3.4 & $4.1 \%$ & $12.6 \%$ & $37.9 \%$ & $25.3 \%$ & $20.1 \%$ \\
\hline 8 & 1.1 & 3.1 & $7.2 \%$ & $20.5 \%$ & $38.2 \%$ & $19.8 \%$ & $14.3 \%$ \\
\hline 9 & 0.8 & 4.5 & $0.3 \%$ & $0.7 \%$ & $11.9 \%$ & $20.1 \%$ & $66.9 \%$ \\
\hline 10 & 1.0 & 3.6 & $3.1 \%$ & $7.2 \%$ & $37.5 \%$ & $28.0 \%$ & $24.2 \%$ \\
\hline 11 & 1.0 & 3.9 & $2.0 \%$ & $5.8 \%$ & $28.7 \%$ & $26.3 \%$ & $37.2 \%$ \\
\hline
\end{tabular}

The average point of Mean in the Question 5-12 in School A is $3.4(>2.5)$ and the average point of Mean in the Question 5-12 in School B is 3.9 (>3.5), which shows that students in School B are relatively more optimistic about the Chinese elements than students in School A.

Questions 13-15 are mainly about whether students think teachers pay attention to cultural teaching in education and teaching and consciously improve cultural teaching skills.

Table 20. School A-Student Questionnaires of Q13-Q15.

\begin{tabular}{|c|c|c|c|c|c|c|c|}
\hline Questions & SD & Mean & Strongly Disagree & Disagree & Not sure & Agree & Strongly Agree \\
\hline 13 & 1.0 & 3.84 & $1.9 \%$ & $7.0 \%$ & $27.8 \%$ & $31.5 \%$ & $31.9 \%$ \\
\hline 14 & 1.1 & 3.68 & $6.7 \%$ & $6.7 \%$ & $26.3 \%$ & $32.6 \%$ & $27.8 \%$ \\
\hline 15 & 1.0 & 4.12 & $2.2 \%$ & $5.2 \%$ & $20.4 \%$ & $22.6 \%$ & $49.7 \%$ \\
\hline
\end{tabular}

Table 21. School B-Student Questionnaires of Q13-Q15.

\begin{tabular}{lllllll}
\hline Questions & SD & Mean & Strongly Disagree & Disagree & Not sure & Agree \\
\hline 13 & 1.1 & 3.8 & $3.1 \%$ & $9.6 \%$ & $24.2 \%$ & $32.1 \%$ \\
\hline
\end{tabular}




\begin{tabular}{llllllll}
\hline Questions & SD & Mean & Strongly Disagree & Disagree & Not sure & Agree & Strongly Agree \\
\hline 14 & 1.1 & 3.8 & $4.8 \%$ & $7.5 \%$ & $26.3 \%$ & $28.3 \%$ & $33.1 \%$ \\
15 & 1.2 & 3.7 & $7.8 \%$ & $6.1 \%$ & $28.7 \%$ & $24.9 \%$ & $32.4 \%$ \\
\hline
\end{tabular}

The average point of Mean in the Question 13-15 in School A is $3.4(>2.5)$ and the average point of Mean in the Question $13-15$ in School B is $3.9(>3.5)$, which shows that students in School B are relatively more optimistic about the Chinese elements than students in School A.

Part 5 External Evaluation-Analysis and Results of Teacher's Interview.

There are 5 questions designed and 15 interviewees participated for this interview. 10 of the interviewees are randomly selected from School A (5 teachers) and School B (5 teachers). 2 headmasters are from School A and School B. 3 experts in the field of basic education are from different universities in Henan Province. The specific interview results are as follows.

Question 1 Do you think it is important for students to master Chinese cultural content in English teaching? About this question, all the interviewees hold the view that it is important for students to master Chinese cultural content in English teaching.

Question 2 Have you ever paid attention to English Curriculum Standard for senior high school? Can you elaborate the requirements of Chinese culture? When Question 2 is asked, $70 \%$ of interviewees paid close attention to NSEFC, but only 3 interviewees could elaborate the requirements of Chinese culture in NSEFC.

Question 3 Do you teach cultural knowledge of Chinese elements in class? What kind of cultural teaching methods are usually adopted? When Question 3 is asked, 90\% of interviewees taught cultural knowledge of Chinese elements in class. And $60 \%$ of interviewees expressed that they just explain the Chinese elements in textbooks, $20 \%$ of interviewees expressed that they usually display cultural background as a supplement to the Chinese elements in textbooks. And others expressed that they designed the diverse teaching activities in English class, such as role-play, Cultural comparison between Chinese culture and foreign cultural awareness.

Question 4 What do you think are the problems in the presentation forms and content selection of Chinese elements in NSEFC? There were 2 of the interviewees had no idea of this question, and others answers can be divided into three type. The first type is Chinese elements contents were not reflected Characteristics of China's new era and the presentation forms is simple. The second types is there were fewer Chinese elements in textbooks and the presentation forms is relatively simple. The third type is Chinese elements contents are not closely related to students' real life, so students were not interested to the Chinese elements contents. And the presentation forms are not very systematic.

Question 5 What suggestions do you have for English textbook compilation in terms of Chinese element presentation forms and content selection? When question 5 is asked, 2 interviewees had no ideas about that. 3 interviewees expressed more Chinese elements contents should be added in textbooks. 4 interviewees hold the view that the section of Chinese elements contents should be more closed to students' real life and in accordance with their age, so they will be interested in Chinese elements in textbooks. 2 interviewees expressed that textbook compilers should present Chinese elements contents more systematically. 2 interviewees suggested that textbook compilers should keep peace with times and deleted outdated Chinese element contents in English textbooks. 2 interviewees suggested that increase the presentation forms of Chinese elements contents.

\section{Conclusion}

This study puts forward that it should increase the proportion of Chinese elements and avoid the singularity of the presentation forms in English textbook, and teachers should use innovative teaching methods in classroom teaching and help students discover more Chinese elements in English textbooks on the different forms of Chinese elements, stratified sampling, with collection and revision. Based on text analysis, questionnaire survey and in-depth interviews above, major findings and suggestions can be drawn as follows.

\subsection{Findings}

1) Both teachers and students in senior high school have high degree of recognition and acceptance towards NSEFC textbooks.

2) Both teachers and students have a certain understanding about Chinese elements in English version. They all agree that English textbooks should contain large amounts of Chinese elements and most of them believe that using pictures are beneficial for strengthening Chinese elements in students' cognition. However, from the text analysis table, it can be seen that very few Chinese elements are presented in the form of "Pictures", the Chinese elements presentation forms are single and fragmented.

3) Senior high school students are very sensitive to Chinese cultural awareness, not only the different countries, but also traditional Chinese culture in different languages. When presenting Chinese elements in NSEFC textbooks, more emphasis can be placed on the depth and breadth of the judgment and leadership of the values of Chinese and Western thoughts, society and culture that can keep pace with the times and the construction of cross-cultural cognitive ability.

4) Both teachers and students have a certain understanding of Chinese cultural education or cultural studying. But in practical English teaching, teachers should focus more on the education of cross cultural awareness and design various cultural teaching activities. 


\subsection{Suggestions}

For English teachers, they need to utilize textbook creatively, have a full understanding of NECS (2017), and enrich Chinese elements introduction methods.

For English textbook editors, they need to update Chinese elements that can reflect the characteristics of China's new era, increase the proportion of Chinese elements in textbooks, try to present Chinese elements in units, instead of using simply information symbol, more charts and diagrams can be supplemented to avoid visual fatigue when presenting Chinese elements. It is also required that extensibility be reflected in the compilation of Chinese elements in English textbooks of senior high schools.

\section{Personal information:}

Gender: School:

Age: $\quad$ Teaching Experience: $\square$ 1-5 years $\square 5-10$ years $\square$ 11-20 years $\square 20$ years or more

2. Here are some descriptions on NSEFC. Please choose your answers according to reality and put a " $\sqrt{ }$ " in the box.

\section{Items Description}

1. I think there are rich cultural contents in the textbooks.

2. I think the cultural contents in the textbooks are closely connected to students' life.

3. I think the cultural contents in the textbooks can deepen students' understanding of their own culture and promote their reflection on cultural difference.

4. I think the cultural contents in the textbook are beneficial for helping students to master related knowledge of language culture.

5. I think Chinese elements are one of the key symbols of traditional Chinese culture.

6. I think it is very necessary to include Chinese elements in textbooks.

7. I think comparing with cultural elements of foreign countries, Chinese elements in the textbooks are richer in contents and more comprehensive in forms of presentation.

8. I thinks the Chinese elements in the textbooks are very up-to-date and they can present the new age and its new characteristics.

9. With regard to the presentation of Chinese elements, I think students prefer the combination of pictures and texts to pure texts.

10. I think there are more cultural elements than natural elements and character elements in the textbooks.

11. I think Chinese elements should be regarded as key contents and presented in units in the textbooks for junior high school students.

12. I think my students have learnt useful English expression of Chinese elements (or Chinese culture) from the textbooks.

13. I think I pay much attention to cultural education when I teach.

14. I think I am good at discovering Chinese elements in textbooks and adding other Chinese elements that are not included in textbooks when I teach.

15. I think the diverse teaching activities I design for the class have helped students to strengthen their understanding of traditional Chinese culture.

Questionnaires for Students:

Questionnaire on Chinese Elements in New Senior English for China (People's education press, 2007).

Dear students:

Hello! Thank you all for answering this questionnaire!

As this questionnaire is part of the research paper, we will only conduct comprehensive statistical analysis on the data collected. Case study will not be performed. Please feel free to answer the questions and be assured that this questionnaire will not result in personal information disclosure as it is anonymous. There's no right or wrong for these questions so please give your answers according to reality. As your opinions are crucial to this thesis, please make sure that all questions are finished. We
Questionnaires for Teachers:

Questionnaire on Chinese Elements in NSEFC-New Senior English for China (People's education press, 2007).

Dear teachers:

Hello! Thank you all for answering this questionnaire!

As this questionnaire is part of research paper, we will only conduct comprehensive statistical analysis on the data collected. Case study will not be performed. Please feel free to answer the questions and be assured that this questionnaire will not result in personal information disclosure as it is anonymous. There's no right or wrong for these questions so please give your answers according to reality. As your opinions are crucial to this thesis, please make sure that all questions are finished. We sincerely thank you for your cooperation!

\begin{tabular}{|c|c|c|c|c|}
\hline $\begin{array}{l}\text { trongly } \\
\text { gree } 5 \\
\text { oints }\end{array}$ & $\begin{array}{l}\text { Agree4 } \\
\text { points }\end{array}$ & $\begin{array}{l}\text { Not } \\
\text { Sure } 3 \\
\text { points }\end{array}$ & $\begin{array}{l}\text { Disagree } 2 \\
\text { points }\end{array}$ & $\begin{array}{l}\text { Strongly } \\
\text { Disagree 1 } \\
\text { point }\end{array}$ \\
\hline
\end{tabular}


sincerely thank you for your cooperation!

1. Personal information:

School: Grade:

Gender:

2. Here are some descriptions on NSEFC. Please choose your answers according to reality and put a " $\sqrt{ }$ " in the box.

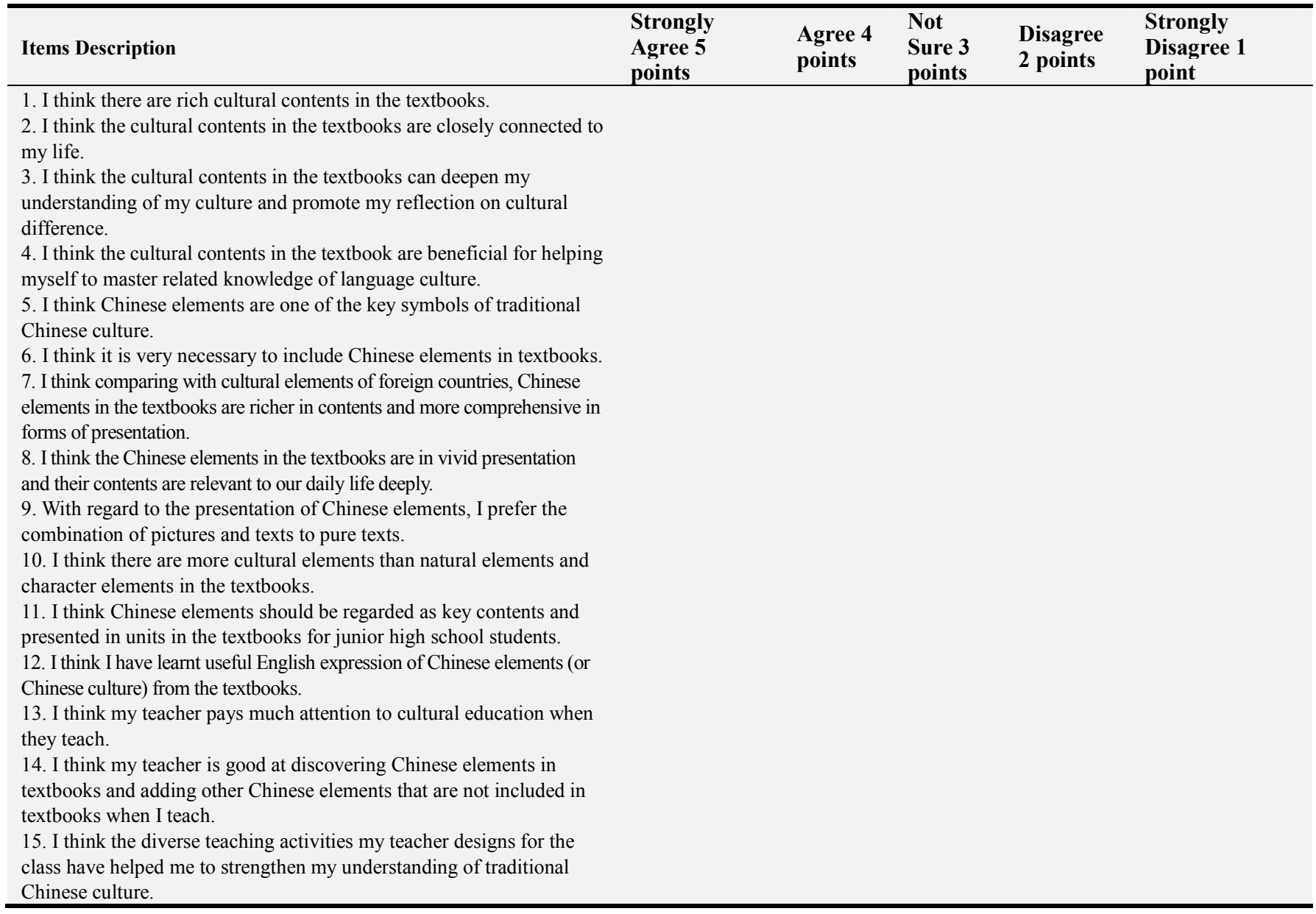

\section{Acknowledgements}

We are grateful for the financial support from Social Science Foundation of Ministry of Education (No. 17YJA740032) and He'nan Social Sciences Planning Project (No. 2018BYY018).

\section{References}

[1] Shanshan Wang. (2011). An Elaboration of the Concept of Chinese Elements. Literature Education, 08: 152.

[2] Cheng Xiaotang. (2002). English textbook analysis and design. Beijing: Foreign Language Teaching and Research Press. 15, 54-64.

[3] Gao Hao. (2012). The Study of the Introduction of Traditional Chinese Culture Elements in textbooks: Take Physics Textbooks as an Example. Journal of Shandong Normal University (Humanities and Social Sciences Edition). 04, 135-139.

[4] Karen, Risager. (2009). Language and culture Pedagogy:
From a National to a Translation Paradigm. The Modern Language Journal, 93 (2), 307-308.

[5] Qian Wang. (2015). Study on the New Model of College English Teaching under the Setting of Multimodality. Universal Journal of Educational Research, 08: 473-477.

[6] Ma Yanming. (2015). The System Composition of the Chinese Element and Related Problems. The big view of advertising. 10, 13-15.

[7] Cui Yiqing. (2010). The Interpretation of the Traditional Chinese Culture Elements in University English Textbooks. Journal of Shenyang Agricultural University (Social Science Edition). 01, 78-81.

[8] Hu Dingrong. (2013). Textbook analysis: Elements, relationships and organizational principles. Curriculum, Teaching Materials and Method, 02: 17-22.

[9] Gao Lingbiao. (2001). The Analysis Model and Category of textbook. Curriculum, Teaching Materials and Method, 03: $1-5$.

[10] Hong Li. (2012). Application of the Multimodal Discourse Analysis Theory to the Teaching of College English Listening and Speaking. IERI Procedia, 02: 319-324. 
[11] Qiao Ailing. (2002). Macroscopic and Microcosmic Design Evaluation of Foreign Language Textbooks. Shandong Foreign Language Teaching. 03: 75-77.

[12] Viorel D, Viorel M. (2015) Scientific Literacy in School. Procedia-Social and Behavioral Sciences, 209: 167-172.

[13] Cunningsworth, A. (2002). Choosing Your Coursebook. Shanghai: Foreign Language Education Press. 102-136.
[14] Liu Daoyi. (2004). Brief Research on Evaluation Criteria of English Teaching Materials. Educational Practice and Research, 12: 14-17.

[15] Zhao Xun. (2008). The Multicultural Education Thought and its influence on Curriculum Theory. Studies in Foreign Education, 12: 14-17. 